\title{
THE EVOLUTION OF CONFUSION: SOFT SYSTEMS METHODOLOGY AND SOCIAL THEORY REVISITED
}

\author{
L. Houghton and P.W.J. Ledington \\ Faculty of Business \\ The University of the Sunshine Coast \\ Pledingt@usec.edu.au
}

\begin{abstract}
Soft Systems Methodology (SSM) is a potentially powerful tool for improving the management of the complex social systems aspect of Information Systems. Yet if it is to be employed effectively IS managers need to understand the theory of social systems that makes SSM a meaningful practical approach. However finding out about that social theory is not straightforward. It is 20 years since the first discussions of the social reality implied by Soft Systems Methodology (SSM) and the area has been given little attention since. Yet SSM itself has progressed dramatically since those first critiques of its underpinning social theory were first developed. This paper revisits the area in order to provide a contemporary perspective and foundation for future development. It reveals apparent weaknesses in the research debate about SSM and social theory, and shows how the evolution of SSM has apparently been affected by that debate. SSM is introduced and examined according to the primary literature and re-evaluated using Burrell and Morgan's four-paradigm matrix of social theory paradigms in order to understand the social reality implied by SSM. The paper examines criticisms of SSM, the recent evolution of SSM, and suggests future directions for development.
\end{abstract}

Keywords: Soft Systems Methodology, Social Reality, Information Systems Management

\section{INTRODUCTION}

Soft Systems Methodology is a potentially powerful approach to facilitating the management of the social systems aspects of Information Systems. The major 'SSM-in-IS' research streams have, however, concentrated upon the application of SSM to Information Systems Development (see for example Checkland \& Holwell 1998, Lewis 1994). The application of SSM within the broader field of IS management is relatively undeveloped by comparison. To develop this area further requires two distinct changes in research focus. First it requires research on treating the Information System and its wider environment as a 'Problem-Situation-to-be-Improved' and applying the principles of SSM towards that end. Second, there needs to be an improved way of transferring the resulting set of SSM-based principles for IS management into the practice of everyday IS managers.

If however Information Systems are viewed as 'Problem Situations' in this way then implicitly they are being treated as 'Social Systems' or at the least as socially constructed artifacts. However just what is meant by the term 'Social System' or 'Social construction' in this context and what implications does the definition of these terms have for Information Systems Management.? To explore this issue further is to ask the question - "what social theory provides the foundation for Soft Systems Methodology?". It is an important question that was addressed to some degree during the early development of SSM yet despite considerable evolution in the principles of SSM it seems not to have been given much recent attention. The aim of this paper is therefore to revisit this question and to provide a contemporary review of the issues involved.

\section{Background}

The Social Reality implied by SSM has been important to the development of the Applied Systems Thinking discipline. It forms the intellectual basis for the distinction between the so-called 'Hard' and 'Soft' approaches and has been seen as a limitation to SSM, which in turn provided intellectual legitimization for to the development of Critical Systems ideas. In this paper we re-visit this important area and by doing so aim to create a clearer understanding of the ways in which the social reality implied by SSM can be addressed. The examination will expose a change in SSM from that of a problem/action orientation to that of Learning System orientation (Checkland and Holwell, 1998, p:12:160). SSM therefore has moved from being concerned with facilitating change in the real world to a focus on learning in the real world. The implications of this change in direction for SSM in terms of social reality need to be clearly understood.

SSM began it's long process of evolution in the late 1960's when traditional methods for systems analysis were found wanting. It was observed that the traditional hard systems methods for organisational problem solving had difficulty in handling the complex nature of real world management problems. A research program into this type of real-world problem situation of a socially rich nature was launched at Lancaster University eventually leading to the establishment of Soft Systems Methodology as a distinctive management approach.

There are many misconceptions about SSM, but the most glaring is the lack of a critical treatment of the radical humanist elements within SSM. In order to examine this area, a paradigm-based examination of SSM is required. Whilst such a treatment was developed originally in Systems Thinking, Systems Practice (see Checkland, $1982 \mathrm{pp} .280-4$ ) it seems as though this area has not been addressed with contemporary SSM and its 
focus on the 'leaming system' (Checkland and Holwell, 1998, p.12:p160) rather than action oriented problem solving (Checkland, 1981, p154:p161). The situation may be a reaction to an argument made against SSM primarily by Prevost (1976) and Jackson $(1982,2001)$. The social reality implied by SSM is seen as interpretive by Jackson and as Functionalist according to Prevost. However Checkland argued that SSM is both interpretive and partially radically humanist (Checkland, 1981, pp.280-4 and Checkland, 1982, p.36-9), although the implications of this position have not been examined in the research literature.

These issues are examined in more detail in the rest of the paper. The examination begins by establishing a basic understanding of SSM based upon the primary and secondary literature. A look at the paradigmatic framework derived from this literature will then be provided and then the evolution of SSM will be examined. These three points lay a foundation for examining the paradigmatic framework in the primary and secondary literature. The section that then follows takes an outward look at criticisms of SSM's paradigmatic framework. A graphical examination of the various points of view will be developed by using Burrell and Morgan's four paradigms as a contextual framework and will allow comparison differing views on SSM's paradigmatic positioning. The paper concludes with a summary of the major points and offers some ideas for future research.

\section{SSM IN THE PRIMARY LITERATURE}

The core texts forming the main body of research-directed work on SSM are: Systems Thinking, Systems Practice (STSP), Soft Systems Methodology in Action (SSMA) and Information, Systems and Information Systems (ISIS) and Soft Systems Methodology: A Thirty Year Retrospective (SSM30). Two main texts form the body of the core secondary literature. Information in Action (Davies and Ledington, 1991) and Systems: Concepts Methodologies and Applications (Wilson, 1984:1990.

SSM according to Checkland

Checkland (1981) argues that the traditional scientific approach to management problems has three major faults. Firstly, there are problems for the scientific method when it comes to complexity because:

"Cursory inspection of the world suggests that it is a giant complex with dense connections between its parts. We cannot cope with it in that form and are forced to reduce it to some separate areas which we can examine separately." (Checkland, 1981, p.60).

Second, reducing the world into separate parts is not feasible in networks of social complexity. Checkland argues that science, both natural and social sciences, ineffectively deal with the social world, especially the organisations in the social world. By this Checkland means 'human activity systems' where humans participate in some purposeful/rational activity, not necessarily companies but groups of humans pursuing purposeful activity. This moves away from the idea that all systems have goals or objectives and towards the idea that these systems of human activity pursue purposeful activity in a social context.

The third area that science fails in is 'Management'. Real world 'management' problems are everyday things that humans have to deal with that simple hypothesis testing to destruction cannot accommodate. More specifically Checkland found that is it useful to divide the world into two types of problems -'Hard' problems and 'Soft' problems. Hard problems are easy to define technical issues that often have specific properties or forms. (Checkland, 1981, p.74) These properties are the same every time and the same solution could be given every time. This means that a hard scientific view of the world could be applied using 'systems ideas' and problem solving could take place. This form of problem-solving approach is termed 'Hard systems thinking'. Soft problems are those other forms of 'management' problem noted above.

The way SSM deals with such social 'management' problems is well-documented. Remembering that Checkland wanted to use systems thinking, he took as his starting point the Complexity, Social Science and Management issues and moved towards a systems approach for real world problem solving. The next ten years were then taken up with the formulation and presentation of SSM. Checkland and associates tested the systems ideas and concepts for problem solving and eventually came up with what is now known as 'Prescriptive' SSM. (Checkland, 1999, A35-A36). The seven stage model of SSM that emerged is an iterative process of flexible learning, not a rigid method. The process of SSM begins with the problem situation and ends with problem situation improved, ideally. This raises questions as to what the methodology hopes to achieve in the real world.

\section{SSM AND IT'S PARADIGMATICAL CONTEXT}

In 1979 Burrell and Morgan published their now classical four-paradigm model of approaches to social reality. Most critics who have tackled SSM have critiqued it according to this model: (Prevost, 1976, Naughton, 1979, Mingers, 1980:1984, Checkland, 1981,p.280, Jackson1982:2001, Flood, 1999). 


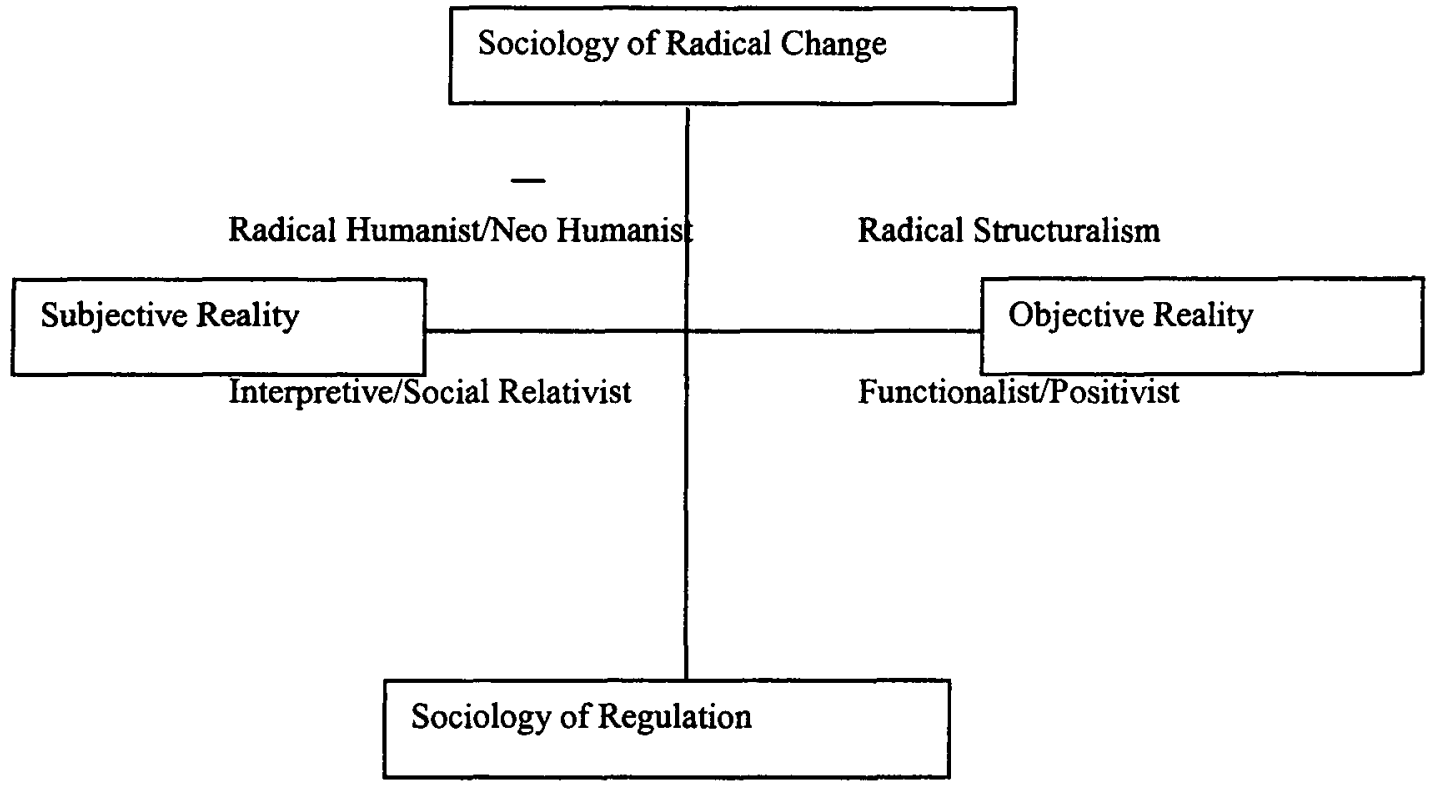

(Burrell and Morgan, 1979, p22)

The Functionalist Paradigm is the dominant framework for social research. It assumes pure functionality and objectivity in the social world. Functionalist schools of thought are what Checkland called 'scientific methods' or the method of science, and Hard systems thinking belongs to this view. The key assumption here for systems theory is that the world is made up of systems that can be engineered.

Interpretive thought is a subjective approach to reality based firmly upon the assumption that social reality is created continually, by humans in the social world. Trying to engineer the unknowable is likened to trying to mow the lawn with tweezers or trying to get a watermelon into a shot glass, it's impossible! The Interpretive Paradigm seems to be the paradigm that has little or nothing to do with action as such, just meaning, and it is important to note that interpretive paradigm sees:

"The social world as an emergent social process that is created by the individuals concerned."

and:

"Social reality, insofar as it is recognized to have any existence outside the consciousness of any single individual, is regarded as being little more than a network of assumptions and intersubjectively shared meanings." (ibid and p.31)

The third, and arguably the most controversial, quadrant of the paradigm matrix is the Radical Humanist Paradigm which embodies many differing doctrines including, anarchy, emancipation, consciousness, antiorganisation theory and existentialism. However:

...it's frame of reference is committed to a view of society which emphasises the importance of overthrowing existing social arrangements. One of the most basic notions of this paradigm is that the consciousness of man is dominated by these ideological superstructures with which he interacts, and that these drive a cognitive wedge between himself and his true consciousness. This wedge is the wedge of 'alienation' or 'false consciousness', which inhibit or prevents true human fulfillment. (Burrell and Morgan, 1979, p.32)

An important part of this view is critical theory. It uses existing disciplines, ideologies and theories to provide a critique of the status quo in order to drive change. This change is supposed to 'emancipate' the human from ideological superstructures of the consciousness imposed on the individual by the social world in which he/she lives. Therefore they:

...seek to change the social world through a change in cognition and consciousness. (Burrell and Morgan, 1979, p.33)

SSM deals with perceptions and not cold hard facts about the real world. Central to this is the idea of the worldviews (or Weltanschauung) in human activity systems. Checkland argues: 
The concept of human activity system is crucially different from the concepts of natural and designed systems. These latter, once they are manifest, 'could not be other than they are', but human activity systems can be manifest only as perceptions by human actors who are free to attribute meaning to what they perceive. There will thus never be a single (testable) account of human activity system, only a set of possible accounts all valid according to particular Weltanschauugen.

(Checkland, 1981, p.14).

The worldview is subjective. So the social reality of SSM is subjective. Looking at the four paradigms, that places SSM in either the radical humanist or interpretive paradigm. The next test is the degree of change that the methodology will perform. According to the primary literature:

“...given the analyst's complete freedom to select relevant systems which, when compared with the expression of the problem situation, embody either incremental or radical change, the area occupied must include some of the subjective/radical quadrant." (Checkland, 1981, p.281).

Before examining criticisms of Checkland's idea of the social nature of SSM, it is important to examine a trend in SSM. This is the move from action based to learning based orientation.

\section{SSM AND IT'S JOURNEY FROM 1981 TO 1998}

SSM as it emerged was presented in the form of a seven-stage model. The seven stage-model was re-shaped into a process involving two streams of action (Checkland and Scholes, 1990, p.29) combined with three streams of analysis in 1988. One of the analyses - The social system analysis - comes straight from the work of Sir Geoffrey Vickers and the appreciative system model (Checkland and Scholes, 1990, p.48). Checkland argues that three things interact with each other, these are: roles, norms and values. Each continually defines, redefines and is itself defined by the other two. (Checkland and Scholes, 1990, p.49) It is a continuous process, out of which the analyst can successfully create a mental picture of norms, roles and values in the organisation. The political system analysis is a variation of the social systems analysis in as much as it is derived from Vickers' model (ibid, p.50). Checkland argues:

"...Analysis Three in the stream of cultural analysis accepts that any situation will have a political dimension, and it needs to be explored." (ibid, p.50)

and politics is taken to be:

“...a process by which differing interests reach accommodation..." (ibid, p.50)

Checkland goes on to add that politics, which is endemic in human affairs, is about managing the relationships between those of differing interests.

The next big advance by 1990 was the invention of mode 2 SSM which is the process that happens when SSM becomes internalised. However, several changes in SSM apparently take place when the shift from mode 1 to mode 2 occurs. Firstly SSM mode 2 users will focus less on intervention and more on interacting in the problem situation, and intensive reflection, and 'using SSM to make sense' (Checkland and Scholes, 1990, p.284).

Mode 2 has permanently changed the focus of SSM, to that of a learning system, as shown below.

\begin{tabular}{|l|l|l|}
\hline Mode 1 & Versus & Mode 2 \\
\hline Methodology driven & Versus & Situation-driven \\
\hline Intervention & Versus & Interaction \\
\hline Sometimes sequential & Versus & Always iterative \\
\hline SSM as an external recipe & Versus & SSM as a internalized model \\
\hline
\end{tabular}

(adapted from Checkland, 1999, A36)

Moreover the learning gained from the situation is the goal rather than change in the real world (see SSMA p.283)

1998

By this stage of the development, SSM has only five stages. (See ISIS p.160) However, the approach now is taken to be five models of purposeful activity molded into one process as a learning system. 
Contemporary SSM contains many of the principles found in previous incarnations but with specific re-wording and the complete demolition of the systems thinking line (See Checkland and Tsouvalis (1997) for a full explanation of this). In this incarnation the focus is on learning and a lot less on intervention and problem solving. This is a decided shift in parts of SSM from Humanism to the Interpretive paradigm.

The original reason SSM was developed was to 'solve' hard to define problems in the real world. Now the focus in SSM seems to be on the learning, and the improvement is not as important

\section{Contemporary SSM}

The contemporary view of SSM is that of ISIS. The constitutive rules of are now described as:

1. you must accept and act according to the assumption that social reality is socially constructed continuously;

2. you must use explicit intellectual devices consciously to explore, understand and act in the situation in question; and

3. you must include in the intellectual devices 'holons' in the form of systems models of purposeful activity built of the basis of declared world views. (Checkland, 1999, A35)

Changes to the existing processes have been suggested by Ledington and Ledington (1999) in the form of Decision Variable Partitioning and Extending the Comparison phase of SSM (1999) but few other theorists have offered any worthwhile contributions to date.

\section{INTERPRETATIONS AND CRITICISMS OF SSM'S PARADIGMATIC FRAMEWORK IN THE RESEARCH LITERATURE.}

The most consistent critic of SSM is critical systems theorist Mike Jackson. In 1982 he suggested, after Mingers (1980) that SSM had no provision for political structure and was limited by it's paradigmatic framework. For example.

"Using Burrell and Morgan's framework I argued soft systems thinking is situated within the interpretive paradigm in that it's guiding assumptions are subjective and regulative." (Jackson, 2001, p.236)

Jackson also argues that because of SSM's conservative bias it would never be able to help the oppressed in anyway. Jackson's critique continued by stating that SSM could not be radical and emancipatory like critical theory but would only help to confirm the status quo because of it's philosophical implications (Jackson 1982).

This philosophical examination of SSM by Jackson was done according to the Burrell and Morgan paradigms. Jackson in essence was arguing that SSM fits into the interpretive paradigm. Checkland presented the methodology as fitting over radical humanism/interpretive paradigms as mentioned earlier. Mingers (1984) opened the debate again. However, Mingers who suggested that critical theory and SSM could share a mutual dialogue (Mingers, 1980) has chosen to focus on the critical systems thinking developed by Jackson.

Jackson says that soft systems methodology has an inbuilt inability to handle complex human and social aspects of social situations then offers no physical evidence to support this claim (ibid, p.235). SSM seems flexible enough to jump paradigmatical boundaries into humanism or even back to functionalism if the user so desires. It is a methodology not a method. At least Checkland some has evidence to support his position (see SSMA Chapters 6,7,8,9 and ISIS Chapter 7 especially). Others have looked at SSM's paradigmatic framework, not to the extent that Jackson did but they are worth noting.

It is interesting to note that Hirshheim et al, (1995) and Ledington and Ledington have both criticized the modeling phases of SSM as too simple and possibly functionalist. Naughton (1979) argued against the case that SSM is functionalist, a charge made by Prevost (1976) but stated that SSM had a whiff of functionalism (Checkland, 1981, p.252).

Despite all these critiques of the social reality implied by SSM there is no evidence from either side to support their the cases. Checkland in 1981 said:

...the comparison will lead to a discussion of possible changes. These are of several kinds, and any combination maybe appropriate in a particular situation. (Checkland, 1981, p.180)

Is this interpretive practice? Checkland argues that it isn't:

...given the analysts complete freedom to select relevant systems which, when compared with the expression of the problem situation, embody either incremental or radical change... (Checkland, 1981, p.281)

This will be limited by a desire for action in the real world (ibid) but the ideals are still humanist ideals. 
Secondly, SSM contains underlying principles that can provide a critique of the status quo in any given organisation. Stage 5 provides a tool for using the systems ideologies against the real world perceptions found in stage 2 . It is hoped that be comparing stage 4 with 2 that a debate will be started about feasible changes. This suggests that SSM is built around rudimentary principles rooted in critical theory.

Mingers (1980) recognized this:

“...three major points of agreement. Firstly both take seriously the problem of human action - at the same time purposive/rational ... and natural or unchangeable as a result of the characteristics of human animal. Secondly, both conclude that hard systems analysis, cannot cope adequately with the multivaried complexities of the real world. Finally both deny the inevitability of the divorce between rationality and the values which characterizes natural science." (Checkland, 1981,p.283)

In order to understand the various perceptions of SSM and its paradigmatic framework, this paper will now present tables that map SSM.

\section{The Mapping of SSM}

The first map presented is that representing the view of Checkland, 1981 .

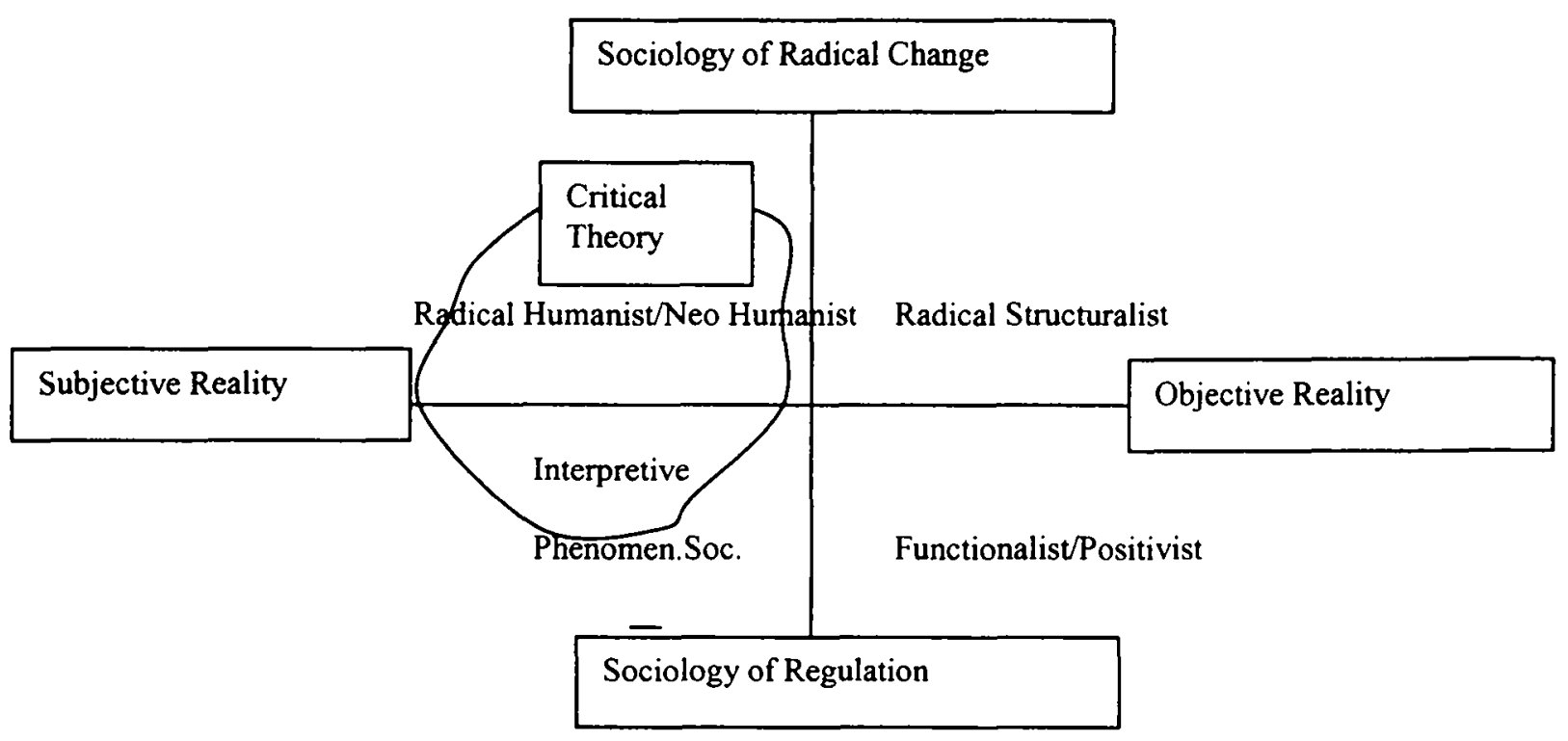

(Burrell and Morgan, 1979, p22)

As previously mentioned Checkland argued that SSM had compatibilities with Critical Theory therefore should be mapped that way. Next is Jackson's case. 


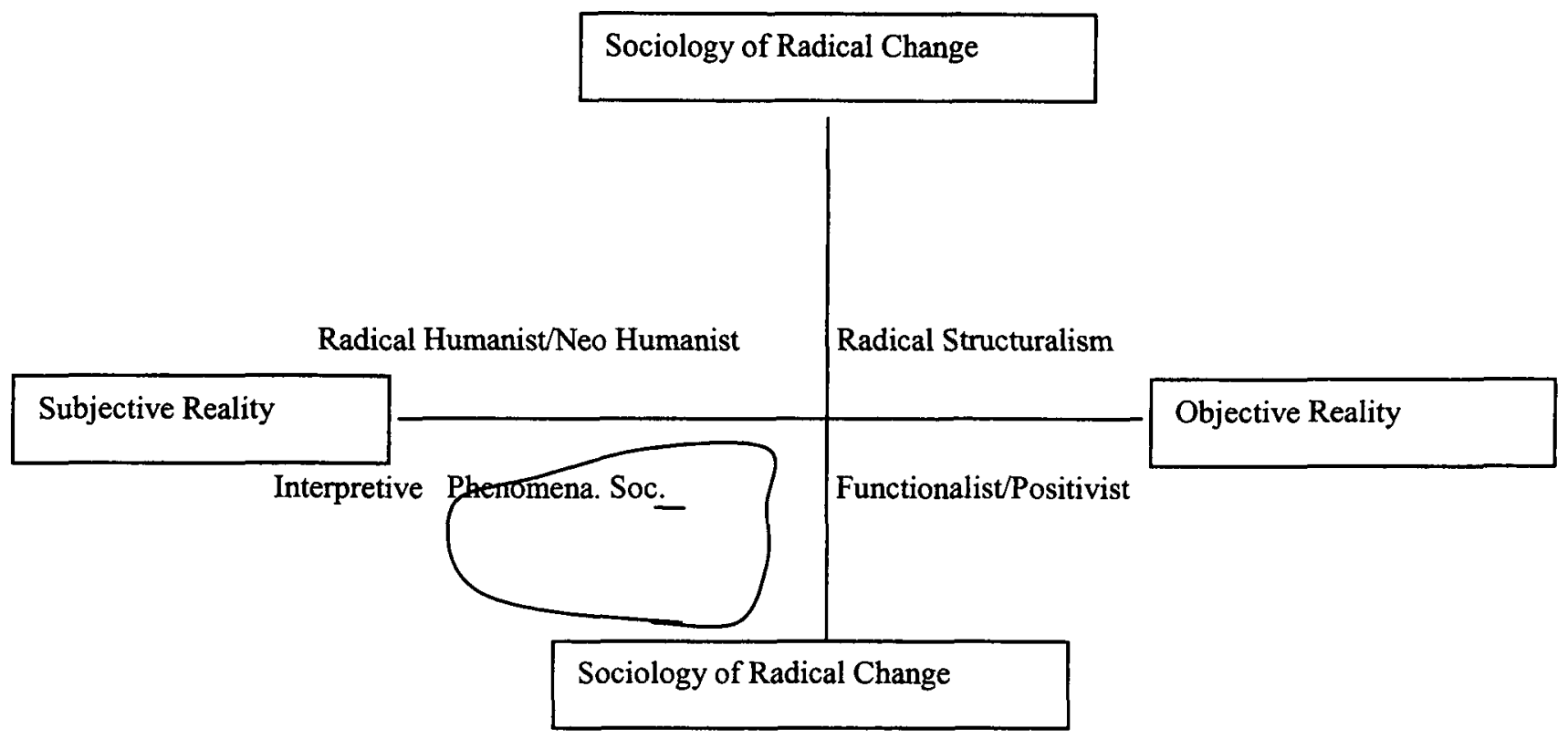

Now the critics of conceptual modeling which are Hirschheim et al. and Ledington and Ledington

Sociology of Regulation

Subjective Reality

Radical Humanist/Neo Humahist Radical Structuralist

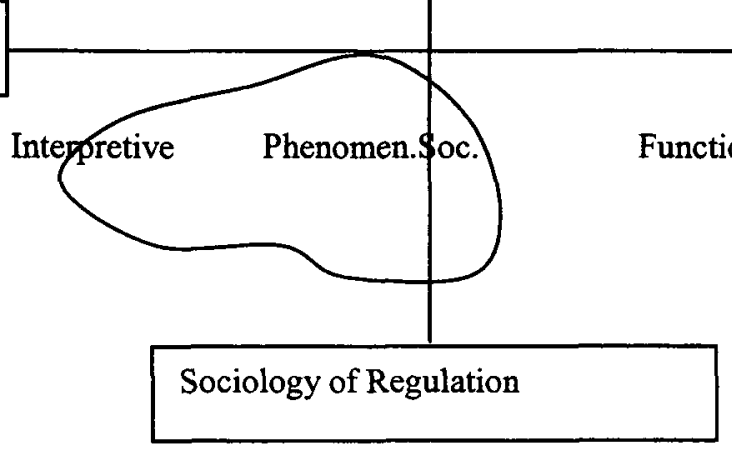

(Burrell and Morgan, 1979, p22)

Hirscheim et al. and Ledington and Ledington have argued that SSM's conceptual modeling is too simple. There is evidence (unlike most critics of SSM's paradigmatic framework) in Ledington and Ledington to suggest this (Ledington and Ledington, 1999) but it is not expressed as a direct argument against SSM's paradigmatic framework. The above is just an assumption derived from the literature and is not explicitly stated. The maps here and the previous section lead to the question. What then is the social reality implied by SSM?

The answer to the question is that the literature is highly confused about SSM and its relation to social theory; which becomes evident when examining the material presented here. There is no agreement as to whether or not SSM is mappable over two paradigms or even one. Jackson provided no evidence for his position and Checkland provided no evidence for his either. SSM has been developed from practice through a process of action research and Checkland continually argues the case for experience being the foundation for the principles of SSM. In this sense it could be argued it reflects the nature of the situations with which it deals. Given that such situations are likely to be much more complex and subtle than the theory that purports to represent them then this apparent 
mis-match between SSM and social theory is understandable. Therefore the conclusion that can be drawn is that the current literature cannot provide a definitive answer to the nature of the social reality implied by SSM and therefore that this area and its contribution to improving the understanding of SSM is ripe for further research efforts.

\section{IMPLICATIONS AND CONCLUSIONS}

The reading of the SSM literature given in earlier sections shows clearly that it can no longer be seen as a singular coherent structure. There are at least three epochs of SSM. We might call them early, middle, and late Checkland Early Checkland is focussed upon the transition from Hard to Soft systems thinking and the formulation of SSM as an iterative seven-stage process. Middle Checkland depicts SSM as a linear two-stream (Cultural analysis and logic-based analysis) process whilst being concerned to make sense of practice in terms of the emergent ideas of formalized, external (mode 1) and informal, internalized (mode 2) types of usage. Late Checkland images SSM as a bare iconic structure of four activities forming a learning process, but with mode 1 and mode 2 embedded as a structure relevant to practice. SSM therefore emerges as phases of evolution each of which involves re-defining the core principles, or constitutive rules, of SSM. It is however far from clear how these three phases interrelate with each other and what implications these changes have for the discussion of underpinning social theory.

The critiques of SSM and its implied social reality are stranded in early SSM and do not address the changes in the later research literature. Further they tend to rely upon the notion of the incommensurability of paradigms as proposed by Burrell \& Morgan. On this basis SSM can only fit into one or other of the four quadrants and cannot reflect aspects of more than one. The evidence examined in this paper suggests however that the relationship between management practice and social theory is perhaps more complex that has previously been assumed. Again the consequences of multi-paradigm mapping and how this might help focus attention on areas of strength and weakness in SSM, and bence provide a basis for seeking to develop it further have not been examined. Further the discussion of this area is sparse, limited, repetitive, and inconsistent. Different authors form different conclusions about the issue, and there is not resolution. The area is clearly problemmatical and confused.

If we accept that thirty years or so of careful development and application, supported by public scrutiny, provides some substance to the claims of SSM then some implications follow. The core that runs through all of the epochs of SSM is that it provides a set of tools for 'structuring', or facilitating (some aspects of) the processes of social construction of reality in a particular context. We must therefore assume that such processes are an inherent part of the context or situation, and that these processes can be more or less effective in generating effective collective purposeful action. In simpler language, SSM operates by improving complex information processing. It is therefore implicitly a fundamental framework for Information Management . In principle it would appear SSM ought to provide a foundation for creating more effective forms of information management. The challenge is to test this proposition in practical situations.

\section{REFERENCES}

Burrell, G and Morgan, G (1979) Sociological Paradigms and Organisational Analysis, Ashgate Press, UK. Checkland, P (1981) Systems Thinking, Systems Practice, John Wiley, UK.

Checkland, P (1982) Soft Systems Methodology as Process: A Reply to M.C. Jackson Journal of Applied Systems Analysis, Volume 9, Department of Systems, University of Lancaster, UK.

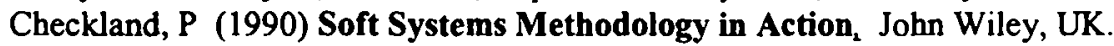

Checkland, P and Tsouvalis, C (1997) Reflecting on SSM: The Link Between Root Definitions and Conceptual Models, Journal of Systems Research and Behavioral Science, Vol 14, no.3, Wiley, UK.

Checkland, P and Holwell, S (1998) Information, Systems and Information Systems, John Wiley, UK.

Checkland, P (1999) Soft Systems Methodology: A Thirty Year Perspective, John Wiley, UK.

Churchman, C. W (1968) The Systems Approach, Delta Publishing, USA.

Davies, L. J. and Ledington, P.W.J (1991) Information in Action, Macmillian, UK.

Flood, R L. (1999) Re-Thinking the Fifth Discipline, Routledge, New York.

Hirschheim, R., Klien, H. K. \& Lyytinen, K. (1995) Information Systems Development and Data Modeling: Conceptual and Philosophical Foundations, The University Press, Cambridge, UK.

Jackson, M C. (1982) The Nature of Soft Systems Thinking: The work of Churchman, Ackoff and Checkland, Journal of Applied Systems Analysis, Volume 9, Department of Systems, University of Lancaster, UK.

Jackson, M C. (2001) Critical Systems Thinking and Practice, European Journal of the Operational Society, Volume 128, Elsevier. 
Ledington, J and Ledington, P.W.J (1999) Decision Variable Partitioning: an alternative modeling approach in Soft Systems Methodology, European Journal of Information Systems, Volume 8, Operational Research Society, UK.

Lewis, P (1994) Information Systems Development 2 Pitman, London

Mingers, J (1980) Towards an Appropriate Social Theory for Applied Systems Thinking: Critical Theory and Soft Systems Methodology, Journal of Applied Systems Analysis, Volume 7, Department of Systems, University of Lancaster.

Mingers, J (1984) Subjectvism and Soft Systems Methodology - A Critique $e_{2}$ Journal of Applied Systems Analysis, Volume 11, Department of Systems, University of Lancaster.

Mingers J (2000) Variety is the spice of life: combining soft and hard OR/MS methods, International Transactions in Operational Research, Volume 7, Pergamon.

Naughton, J (1979) Functionalism and Systems Research: a comment, Journal of Applied Systems Analysis, 6, Department of Systems, University of Lancaster.

Prevost P( 1976) "Soft" Systems Methodology, functionalism, and the social sciences,_Journal of Applied Systems Analysis, 5, Department of Systems, University of Lancaster.

Wilson, B (1984) Systems: Concepts, methodologies and applications, Chichester, Wiley.

Wilson, B(1990) Systems: Concepts, methodologies and applications: Second Edition ${ }_{2}$ Chichester, Wiley. 